\title{
Bernhard Gross and his Contribution to Physics in Brazil
}

\author{
Sergio Mascarenhas \\ Instituto de Estudos Avançados \\ Caixa Postal 440 \\ Universidade de São Paulo, São Carlos, SP, Brazil and \\ CNPDIA, Embrapa, São Carlos, SP, Brazil \\ Received 3 December, 1998
}

Most of the following lines were originally written in 1985-1986 [1]; now in 1998, on the invitation of $\mathrm{R}$. Gerhard-Multhaupt, G. F. Leal Ferreira, and R. M. Faria, I have the honor to write another contribution about Bernhard Gross, this time for a special issue of the Brazilian Journal of Physics dedicated to him. Between 1985 and 1998, Professor Gross has again accomplished a number of marvelous scientific results: Besides other things, he supervised three Ph.D. theses and published a total of nineteen papers in well-known international journals. He also initiated other new lines of research as dynamical methods for the investigation of electron emission from metal or polymer surfaces and for the experimental study of electrical effects in solid dielectrics upon low-energy electron irradiation, besides several theoretical contributions with his close friend, colleague, and neighbor Guilherme Leal Ferreira. Incidentally, the friendship or, best put, the love, which permeates the Bernhard Gross Electrets and Polymers Laboratory in São Carlos and which was induced by Bernhard Gross himself, is a magnificent example of how science can (and should!) be cultivated together with humanity.

When Bernhard Gross arrived in Rio de Janeiro in Brazil in 1933, he was a young physicist from Stuttgart, full of enthusiasm and creativity. He was about to start the tradition of physics research in Brazil and also to provide one of the most important examples of scientific development in Latin America. However, his work was not to be confined to Brazil alone. Due to his multiple interests and the high quality of his research, Gross extended his contributions to an international level, and there are no better proofs of the world-wide importance and recognition of his work than the $3 \mathrm{rd}$ and the 5 th International Symposia on Electrets (ISE 3 and 5), held in São Carlos, Brazil, in 1975 and in Heidelberg, Germany, in 1985, respectively, to honor Gross on the occasions of his seventieth and eightieth birthdays, respectively, as well as the three editions of the book "Electrets" edited by Gerhard Sessler in 1980, 1987, and 1998/1999, respectively, and dedicated to Bernhard Gross who himself contributed two essential chapters to them (see below), and two special journal issues dedicated to him in 1996 [2] and in 1999 (this issue).

There are many aspects of the life of Bernhard Gross that are unique for him as a man and as a scientist. Here, I should like to mention some of the many facets of his personality, without bothering to separate systematically his scientific accomplishments from his life as a human being. Perhaps this is the best way to speak about Gross anyway. First, there is his decision to come to Brazil in 1933. Today, with jets crossing the oceans within a few hours, one cannot imagine what it meant to go to another continent, to a far-away and under-developed country. Travel was possible only by sea and it would take weeks for mail to reach Brazil from Europe. His adventurous spirit, not immediately apparent in the shy external appearance of Bernhard Gross, is not common to scientists who are usually always looking for safe conditions to work and to build careers. Mind you, Gross learned his Portuguese only after arriving in Brazil! After one year, in 1934, he was already doing his research and publishing a paper on cosmic radiation in the Annals of the Brazilian Academy of Sciences.

As a scientist from the Third World, I know many promising scientists with brilliant performance in advanced countries who, on coming to the relative isolation of our region, without the atmosphere of continuous exchange or the other excellent conditions of their societies, do not produce a single contribution anymore. It may well be that, in order to develop your creativ- 
ity as an individual in science, an experience of these limited conditions is very enlightening. Or is it because you want to find new, untapped areas of research, away from the publish-or-perish battle of advanced environments? The case of Gross may be a combination of all these parameters, together with a nostalgic and sentimental aspect: His aunt had brought him on a visit to Brazil when he was a child, and perhaps the images of this tropical and mysterious country lingered in his mind ever since. The fact is that Gross worked very hard in Brazil, and he soon managed to organize the first course in Physics in Rio and started to build a research group working on cosmic rays, a subject he knew extremely well from his thesis work, and later on in dielectrics, viscoelasticity, applied mathematics, and scientific instrumentation.

I should like to mention that this is another main aspect of Gross' life: Interdisciplinarity and his ability to perform equally well both as an experimentalist and as a theoretician. It arises from his true interest, motivation and curiosity for the investigation of nature. For him, science is a way to satisfy this curiosity, not a collection of compartmentalized disciplines. He worked on cosmic rays, and the Gross Transform was a most important contribution, mentioned in all the relevant international literature. In the theory of dielectrics, where he excelled as he did in other areas, not only the formal results that Gross obtained were fundamental from a mathematical standpoint, but he also proceeded to accomplish many of the more important experimental confirmations of such concepts as the theory of dielectric absorption, thermally stimulated currents and voltages, electrets, and related subjects.

Gross also worked in rheology, and his book on the mathematical structure of theories of viscoelasticity is a classic. I can never forget that when I was a visiting professor at MIT, a colleague who is an expert in rheology, Prof. I. Yannas, asked me whether I knew B. Gross since I was from Brazil. When I told him that I considered myself a member of the Gross school in Brazil, he asked me how he could contact Gross. By chance, Gross was just on one of his scientific exchange visits to Bell Laboratories, so he was invited to come to MIT in order to be known personally by the students to whom Yannas was teaching the "Gross model" of viscoelasticity. In relation to viscoelasticity, I always remember the story that Gross, after having finished his book by working very hard during the Carnival holidays in Rio, asked one of his collaborators, who was going to Paris, to take the original manuscript to the publisher in France. It turned out that the person lost the manuscript on the Paris Metro!

Gross influenced many young scientists in Brazil, and soon created a veritable school in Rio, with J. Costa Ribeiro, P. Rocha, A. D. Tavares, O. Castro, and others of that generation. Later on, when I worked with J. Costa Ribeiro in the 1950s, I met Gross for the first time. At that time, he inspired Costa Ribeiro who found the phenomenon that is now called Costa Ribeiro effect, the occurrence of currents and voltages during phase transitions in dielectrics. Gross also made important contributions to the understanding of this phenomenon. When I came to start my own research group in São Carlos, inland of São Paulo, a further step of isolation from Rio, I brought with me and my early companions Yvonne Mascarenhas, Guilherme Leal Ferreira, E. Rodrigues and others the spirit that Gross had implanted in Rio two decades earlier. It was a great honor and permanent inspiration for us when Gross came to São Carlos in the 1970s to work with us and to teach a completely new generation of physicists.

Focusing again on his interdisciplinarity, Gross is always very keen on mathematical aspects of science. He was one of the first to understand the famous Dirac delta function from the standpoint of integral analysis. He was also one of the first, together with W. Guttinger, then visiting Brazil, to apply distribution theory, at that time a highly sophisticated and recent mathematical abstraction, to the theory of linear systems. This, by the way, was another field where Gross made fundamental contributions, well known world-wide.

As if these many contributions were not sufficient, Gross was also very important for the creation of the National Research Council of Brazil, which changed the scientific development of our country. In addition, he was instrumental in the establishment of the National Nuclear Commission of Brazil and the National Institute of Technology. But he never stopped his science.

Another different and very important contribution of Bernhard Gross was when he went to Europe in the 1960s. For seven years, he was Director of the Division of Scientific and Technological Information of the International Atomic Energy Agency (IAEA) in Vienna. Gross was one of the first to apply modern information technology to science, creating the International Nuclear Information Service (INIS) with the participation of more than one hundred member states of the international agency. He was the Director of the Organizing Secretariat for the Conference on the Peaceful Uses of Atomic Energy, and his influence in Vienna was recognized when he received a special honor during the commemoration of the 20th anniversary of the IAEA in Vienna in 1977.

After having returned to Brazil from Vienna, he started his work as a multi-national scientist: work- 
ing in Brazil, at São Carlos, University of São Paulo, in close collaboration with G. F. Leal Ferreira, M. S. Campos, R. A. Moreno, R. M. Faria, J. A. Giacometti, M. T. Figueiredo, L. N. Oliveira, and many others. In São Carlos, we have also introduced the concept of the bioelectret and investigated the presence of electrets in biological systems.

As mentioned before, in this new phase of his life, Bernhard Gross collaborated with Gerhard Sessler, Jim West and their group at Bell Laboratories. Both in São Carlos and at Bell Labs, he investigated the interaction of radiation with insulators in detail, extending his studies to polymers. Again we find his constant characteristic: association of theory and experiment. His interest in the interaction of radiation with matter started of course from his early studies on cosmic rays in Europe and Brazil. This was continued when he found important charge-storage effects in glasses and polymers (radioelectret). In the decade after 1969, he influenced the creation of a group in Rio at the Catholic University to which Preston Murphy came from the United States. This group, I think, was also instrumental for future contributions in the field of applied electret technology. In the same field of interaction of radiation with dielectrics, Gross introduced the concept of Compton currents and proved their existence experimentally. With that result, he was able to propose and build the Compton dosimeter, now in wide use for high radiation fields. When, at the end of the 1970s, G. Sessler organized, directed and edited the book on Electrets published by Springer- Verlag, Gross contributed a monumental chapter on radiation effects; he also was a co- author of a timely update chapter to the second edition of the book in 1987. The third edition which is just now being published by Laplacian Press (to appear in early 1999) still contains these two important chapters and is again dedicated to Bernhard Gross by his fellow contributors.

Stuttgart, Rio, Vienna, São Carlos, Murray Hill, Boston (where he was a visiting scientist at MIT), Darmstadt, and many other places and countries are his home, but science is his world, with no frontiers and no restrictions of race or nationality. Gross has published more than 200 papers, and only after 1980 more than 40 of his contributions appeared in the international literature.

With so many contributions to science, Bernhard Gross received many honors as the Houssay Award from the Organization of American States, the Fellow grade of the American Physical Society, the Whitehead Award, the Guggenheim Award, Doctor Honoris Causa of the University of São Paulo and of the Darmstadt University of Technology, Member of the Brazilian Academy of Science, Emeritus Member of the Academy of Science of São Paulo, and many others.

He never loses his interest in all subjects, from music to literature, the international situation, cinema and of course science. His wife Gertrude Gross and his two sons Antonio and Roberto (very typically, one in Canada and the other in Vienna now) are his family. Gertrude and Bernhard had the pleasure of seeing their gracious grand-daughter Vanessa grow up and recently enter university in Canada. But Gross has also grown a vast scientific family with many generations, all over the world. I think the idea of editing this special issue of the Brazilian Journal of Physics to honor Professor Gross is a way to present his work and to thank him for all he has done for science and culture during all these years.

Please, allow me to conclude in Portuguese, the language of Brazil, the country Gross helped so much to develop, thus giving an example of social solidarity in this troubled and divided world: "Muito obrigado e muitas felicidades Gertrude e Bernhard Gross."

\section{References}

1. S. Mascarenhas, "Bernhard Gross: The Man and the Scientist", IEEE Trans. Electr. Insul. EI21, 243 (1986).

2. CEIDP Digest of Literature on Dielectrics, "Electrets, Charged or Poled Dielectrics and Their Applications", IEEE Trans. Diel. Electr. Insul. 3, 601-734 (1996). 